\title{
Empirical Analysis of the Dynamic Impact of Stock Market Sectors Order Flow on Return
}

\author{
Chenggang $\mathrm{Li}^{\mathrm{a}}$, Di Wang ${ }^{\mathrm{b}^{*}}$, Min $\mathrm{Li}^{\mathrm{c}}$, Bing Yang ${ }^{\mathrm{d}}$ and Kang Pan ${ }^{\mathrm{e}}$ \\ Faculty of Finance, Guizhou University of Finance and Economics, Guiyang, China \\ a895977948@qq.com, b386954277@qq.com, '649747376@qq.com, d2431605045@qq.com, \\ e329223265@qq.com \\ *The corresponding author
}

Keywords: Sector; Order flow; Return; Dynamic effect; VAR model

\begin{abstract}
The research on the impact of the sector order flow to the sector return is beneficial to investors who understand the inner mechanism of the stock sector rotation, and to provide decision-making basis for investors who choose stock sectors. Using the VAR model, this paper empirically analyzes the influence of stock market sector order flow on the sector return, and reveals the dynamic impact process of sector order flow on sector return. The empirical results show that the sector order flow is significantly positive influence on the sector return. The impact process of sector order flow on the sector return is dynamic.
\end{abstract}

\section{Introduction}

In China's stock market, the sector rotation phenomenon is very significant. The sector return of every trading day is constantly changing. This shows that the fund flows between the different sectors, which produce the sector rotation phenomenon. The fund flowing between sectors prompts the changing sector return. This article adopts the sector order flow that depicts the flow of funds in different sectors, and studies the impact of sector order flow on the sector return. Researching the impact of sector order flow on the sector return is beneficial to investors who understand the inner mechanism of the stock market sector rotation, and provides decision-making basis for investors who choose stocks sector.

\section{Literature Review}

Many scholars have deeply studied the influence of stock order flow on the return. From the point view of order imbalance, Chordia et al. (2002) [1] discuss the New York stock market trading activities, and found the market return is affected significantly by the same period and lag order flow. Although after the control of the sum volume and order liquidity, the market returns are still under the influence of order imbalance. Harford and Kaul (2005) [2] study the US stock market, and find that the stock order flow can explain the stock return. By same time, the stock market index order flow, such as the S\&P 500 index stock order flow, have more significant influence on the overall market return than the non-index stocks return. Bailey etc. (2009) [3] empirically test the relationship between the Shanghai stock market return and order imbalance, as well as the generality of individuals, institutions and property investors order imbalance. The results show that order imbalance of the institutional investors (property right) has greater influence on return, and the generality of individual investors order imbalance is stronger. Li et al (2011) [4] use event study analysis to study the stock characteristics which are recommended by the securities analysts. They find that the symbols of abnormal return and abnormal order flow of stocks that securities analysts recommend are the same, and are significant under $1 \%$ level. Then the stock selection method based on the order flow is proposed. Luo et al (2011) [5] analyze the interaction relationship of order flow, liquidity and return between different market value stocks, and find that small-cap stocks rise, then order flow large-cap stocks returns drop significantly in the future. Li et al (2011) [6] and $\mathrm{Li}$ et al $(2015)^{[7]}$ think a stock order flow impacts the stock returns, and build the portfolio model and 
dynamic investment strategy based on the order flow respectively. They also proves the effectiveness of the portfolio model and dynamic investment strategy.

It can be seen from the above scholars' research, the stock order flow have significant impact on return. However, these scholars have not researched the influence of the stock sector order flow on sector return, and not researched the dynamic impact process of sector order flow on return. Therefore, this article uses the Vector autoregressive model (VAR) to empirically analyze the influence of order flow on the return, and reveal the dynamic impact process.

\section{Empirical Test on the Dynamic Influence of Sector Order Flow on Return}

Variables Selection and Their Treatment. To test the impact of sector order flow on the sector return, and analyze the influence of sector order flow on return, we select to two variables which are sector order flow and sector return.

(1) Sector returns (R). We use the following formula to calculate sector return:

$R_{i t}=\log P_{i t}-\log P_{i t-1}$

Where, $R_{i t}$ for the Tth day of the Ith tectonic sectors' return; $P_{i t}$ is closing price for the Tth days of the Ith sector index

(2) Sector order flow (OF). First of all, according to Lee and Ready (1991) [8], the method of judging the direction of each transaction is initiated by the buyer or the seller. We will each deal clinch a deal valence comparing with trade quotes halfway point, if the price is higher than the quote midpoint, we think the deal initiated by the buyer; If the price is lower than the price point, we believe that the deal was sponsored by the seller. Because calculating the difference of transaction initiated by the buyer and the seller, so this article only to identify with the different deal of price quote midpoint and trasaction price. Reference Evans and Lyons (2002) [9], Underwood (2009) [10], Dijun Tan and Yixiang Tianc (2009) [11], the method of this paper, it defined every transaction initiated by the buyer and the seller of balance of transaction amount as the flow of the order on the day. The whole sector order flow is the weighted average of sector inside for all the stock order flow.

Data Sources. This paper selects daily data of all sectors index in China's stock market, and chooses October 1, 2010 - December 31, 2011 as data time interval. For this study, the data comes from Guo Tai An CSMAR high-frequency database in China stock market and RESSET financial database.

Model Building. In order to reflect the impact of the sector order flow on the sector return, the paper establishes a two variable vector autoregressive model as follow:

$$
\left[\begin{array}{c}
R \\
O F
\end{array}\right]=\left[\begin{array}{l}
c_{1} \\
c_{2}
\end{array}\right]+\left[\begin{array}{ll}
\pi_{11} & \pi_{12} \\
\pi_{21} & \pi_{22}
\end{array}\right]\left[\begin{array}{c}
R_{t-1} \\
O F_{t-1}
\end{array}\right]+\left[\begin{array}{ll}
\theta_{11} & \theta_{12} \\
\theta_{21} & \theta_{22}
\end{array}\right]\left[\begin{array}{c}
R_{t-2} \\
O F_{t-2}
\end{array}\right]+\cdots+\left[\begin{array}{ll}
\phi_{11} & \phi_{12} \\
\phi_{21} & \phi_{22}
\end{array}\right]\left[\begin{array}{c}
R_{t-p} \\
O F_{t-p}
\end{array}\right]+\left[\begin{array}{c}
\mu_{1} \\
\mu_{2}
\end{array}\right]
$$

In this formula, the return of sector is represented by R. The sector order flow is shown by OF. $\pi$, $\theta$ and $\varphi$ mean unknown parameters. $\mu$ means error term.

Empirical Analysis. (1) VAR model estimates

This article uses model (2) to analyze how sector order flow affects sector return. We need to gain lag intervals for endogenous before estimating model (2). Using Logit, LR, FPE, AIC, SC and HQ to gain the optimal autoregressive lag order. The test result of the optimal lag order of VAR model which lags $0-5$ orders as shown in table 1 .

NOTE: LR represents the likelihood ratio statistic, FPE represents the final prediction error statistics, AIC means the statistics of Akaike information criterion, SC represents the statistics of Schwartz guidelines, HQ represents Hannan Kun information criterion statistics. This article uses statistics above to gain lag phase.

Table 1 shows that: at the 5\% significance level, with reference to the various information criterion values, VAR autoregressive model optimal lag order is 3. Therefore, the VAR model which tests the impact of the sector order flow to sector return is: 
Table 1. The determination of lag order

\begin{tabular}{|c|c|c|c|c|c|c|}
\hline Lag order & $\log \mathrm{L}$ & LR & FPE & AIC & SC & HQ \\
\hline 0 & 43.8932 & NA & 0.3280 & 4.3244 & 2.5009 & 11.3853 \\
\hline 1 & 42.9290 & 23.8201 & 0.3273 & 4.3185 & 2.4943 & 11.3641 \\
\hline 2 & 42.0039 & 23.2339 & 0.3264 & 4.3107 & 2.4882 & 11.3562 \\
\hline 3 & 39.1205 & 23.2188 & 0.3255 & 4.3083 & 2.4793 & 11.3507 \\
\hline 4 & 41.9302 & 23.2299 & 0.3268 & 4.3194 & 2.4827 & 11.3588 \\
\hline 5 & 42.5816 & 23.6257 & 0.3291 & 4.3206 & 2.4955 & 11.3615 \\
\hline
\end{tabular}

$\left[\begin{array}{c}R \\ O F\end{array}\right]=\left[\begin{array}{l}c_{1} \\ c_{2}\end{array}\right]+\left[\begin{array}{ll}\pi_{11} & \pi_{12} \\ \pi_{21} & \pi_{22}\end{array}\right]\left[\begin{array}{c}R_{t-1} \\ O F_{t-1}\end{array}\right]+\left[\begin{array}{ll}\theta_{11} & \theta_{12} \\ \theta_{21} & \theta_{22}\end{array}\right]\left[\begin{array}{c}R_{t-2} \\ O F_{t-2}\end{array}\right]+\left[\begin{array}{ll}\phi_{11} & \phi_{12} \\ \phi_{21} & \phi_{22}\end{array}\right]\left[\begin{array}{c}R_{t-3} \\ O F_{t-3}\end{array}\right]+\left[\begin{array}{c}\mu_{1} \\ \mu_{2}\end{array}\right]$

Using Eviews6.0 estimation model (3), and estimate results are shown in table 2.

Table 2 The result of estimating VAR (3) model

\begin{tabular}{|c|c|c|}
\hline & $O F$ & $R$ \\
\hline \multirow[t]{3}{*}{$\mathrm{C}$} & 0.0884 & -0.0014 \\
\hline & $(0.0456)$ & $(0.0212)$ \\
\hline & {$[1.9374]$} & {$[-0.0638]$} \\
\hline \multirow[t]{3}{*}{$O F \quad(-1)$} & $0.2506 * * *$ & $0.2324 * *$ \\
\hline & $(0.2578)$ & $(0.1199)$ \\
\hline & [2.9721] & [1.9387] \\
\hline \multirow[t]{3}{*}{$O F \quad(-2)$} & -0.0874 & $0.0105 * *$ \\
\hline & $(0.2763)$ & $(0.1285)$ \\
\hline & {$[-0.31633]$} & [2.0819] \\
\hline \multirow[t]{3}{*}{$O F \quad(-3)$} & 0.0737 & $0.0101 * *$ \\
\hline & $(0.2401)$ & $(0.2015)$ \\
\hline & {$[1.2594]$} & [1.9983] \\
\hline \multirow[t]{3}{*}{$R \quad(-1)$} & $0.0208 * * *$ & $0.2322 * *$ \\
\hline & $(0.5376)$ & $(0.2499)$ \\
\hline & {$[-3.13862]$} & [ 1.9288] \\
\hline \multirow[t]{3}{*}{$R \quad(-2)$} & $-0.1787 * * *$ & -0.1623 \\
\hline & $(0.5300)$ & $(0.2464)$ \\
\hline & {$[-2.33716]$} & {$[-0.6587]$} \\
\hline \multirow[t]{3}{*}{$R \quad(-3)$} & 0.0399 & $0.1142 * *$ \\
\hline & $(0.7326)$ & $(0.5258)$ \\
\hline & {$[0.5927]$} & 1.9722 \\
\hline R-squared & 0.9743 & 0.8450 \\
\hline Adj. R-squared & 0.9739 & 0.8082 \\
\hline Sum sq. resids & 0.6013 & 0.1300 \\
\hline S.E. equation & 0.1551 & 0.0721 \\
\hline F-statistic & 562.5013 & 47.0599 \\
\hline Log likelihood & 16.0805 & 39.0574 \\
\hline Akaike AIC & -7.7387 & -2.2705 \\
\hline Schwarz SC & -7.5052 & -2.0370 \\
\hline Mean dependent & 0.0690 & -0.0181 \\
\hline S.D. dependent & 0.1497 & 0.0724 \\
\hline
\end{tabular}


Note: values in ( ) mean standard deviation, values in [ ] mean t-statistic. $* * *$ and $* *$ show significant at the level of $1 \%$ and $5 \%$ respectively.

From the point of the estimated result of table 2, respectively adjusted r-squared figures are 0.9739 and 0.8082 , F statistics are 562.5013 and 47.0599 respectively, which show that the model fitting effect is good. AIC and SCI values are relatively small, indicating lag order model selected is reasonable. At the same time, by calculating the AR characteristic polynomial of VAR (3) model, we find the reciprocal of the root of the characteristic polynomial are all located within the unit circle (as shown in figure 1), which proves that the VAR (3) model established is stable. That is: When a variable changes in the model (generate an impact), other variables will change, but as time goes on, the impact will gradually disappear. Thus, despite the factors affecting the sector return complex, as a whole, the VAR system which is composed by sector order flow and sector return is stable.

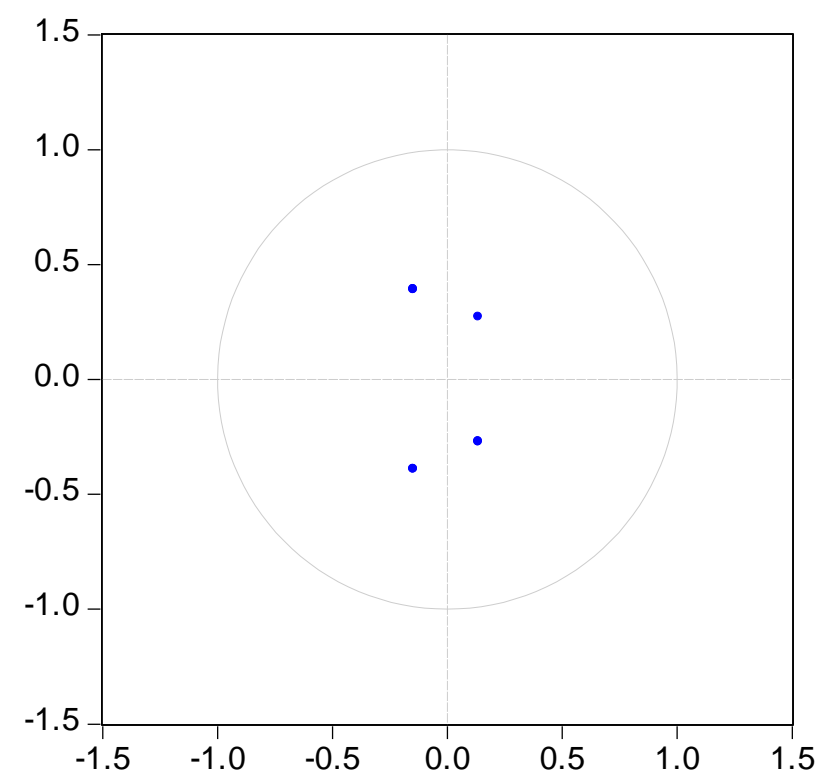

Figure 1. VAR (3) AR characteristic polynomial inverse model figure

From the estimation result of VAR(3) model in Table 2, it can be found: the influence coefficient of the sector order flow lagging one order for sector return is 0.2324 , the influence coefficient of the sector order flow lagging two order for sector return is 0.0105 , the sector order flow lagging three order for sector return is 0.0101 . This shows that sector return may be more influenced by first-order sector order flow than second-order and third-order, and the influence of the sector return will decrease gradually with the increasing lag. Besides, the first-order, second-order and third-order sector order flow impact on return at the $5 \%$ are significant, and has positive effect.

(2)Dynamic impact process analysis

In order to make the impact more intuitive, this paper uses impulse response function, which is based on the estimates of VAR (3), as shown in Figure 2. As can be seen from the figure 2, the sector order flow impact to the return decrease gradually, in the second period to achieve the minimum value, and then increases gradually, in the fourth phase of the sector order flow impact to the return reached a relatively large value, after the fifth phase, the sector order flow impact to the return gradually disappear. 


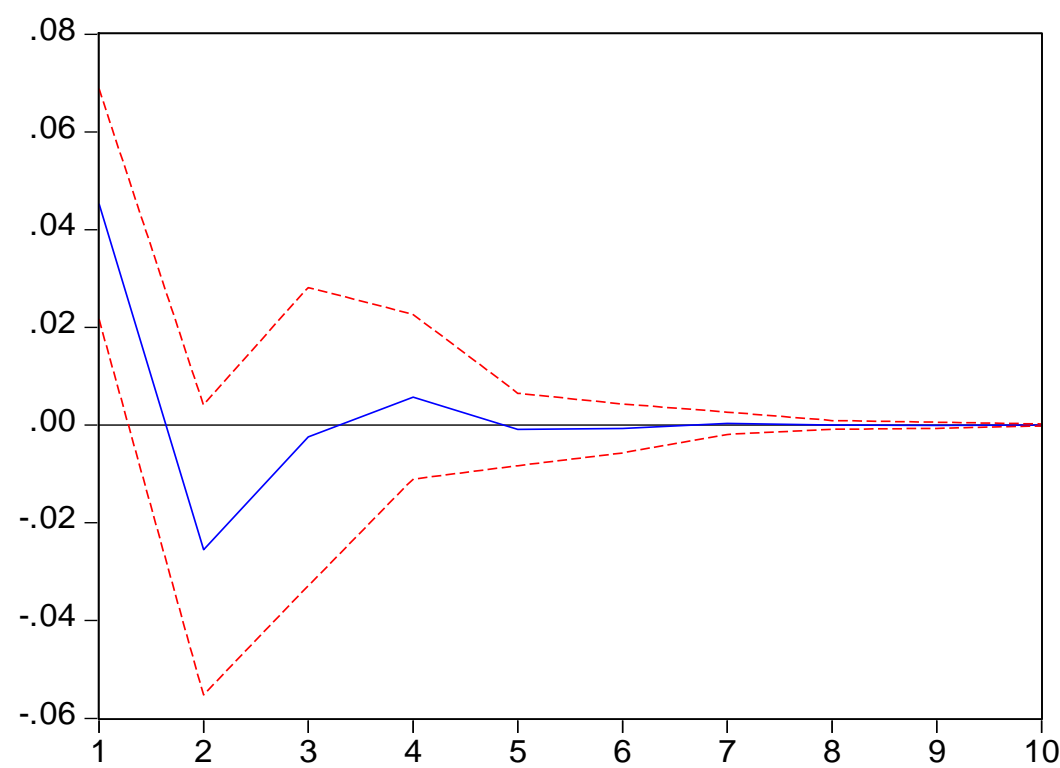

Figure 2. The response function of sector order flow and return

As the above test result shows, sector order flow has significance effect on sector return, and the impact is a dynamic process.

\section{Conclusions}

This paper uses VAR model to empirically analyzes the influence between stock market sector order flow and return, and reveal the dynamic impact process. The empirical results show that sector return may be more influenced by first-order sector order flow than second-order and third-order. The influence of the sector return will decrease gradually with the increasing lag period. The sector order flow has significant impact on sector return, and has positive effect. The impact of sector order flow on the sector return is a dynamic process.

\section{References}

[1] T. Chordia, R. Roll, A. Subrahmanyam. Order imbalance, liquidity and market returns [J]. Journal of Financial Economics, 2002, 65(1): 111-130.

[2] J. Kaul. Correlated order flow: Pervasiveness, sources, and pricing effects [J]. Journal of Financial and Quantitative Analysis, 2005, 40(1): 29-55.

[3] W. Bailey, J. Cai, L. C. Yan, et al. Stock returns, order imbalances, and commonality: Evidence on individual institutional, and proprietary investors in China $[\mathrm{J}]$. Journal of Banking \& Finance, 2009, 33(1): 9-19.

[4] C. Li, Y. Tian, C. Luo, et al. Comparative Study on Order Flow and Analyst Stock Selection Return based on NBC [J]. Systems Engineering, 2011, 29(11): 7-14.

[5] M. Luo, Y. Tian, F. Jin, et al. Order Flow, Liquidity and Flight on the Stock Market [J]. Management Review, 2011, 23(7): 131-137.

[6] C. Li, Y. Tian, C. Luo. Security Investment Optimal Portfolio Model under Order Flow Impact and Its Application Study [J]. Systems Engineering, 2011, 29(6): 17-21.

[7] C. Li, C. Luo, J. Hu. Dynamic Investment Strategy Based on Order Flow and its Empirical Study [J]. Chinese Journal of Management Science, 2015, 30(4): 148-156. 
[8] C. Lee, M. Ready. Inferring trade direction from intraday data [J]. Journal of Finance, 1991, 46(2): 733-746.

[9] M. Evans, R. Lyons. Infromational integration and FX trading [J]. Journal of International Money and Finance, 2002, 21(6): 807-831.

[10] S. Underwood. The cross-market information content of stock and bond order flow [J]. Journal of Financial Markets, 2009, 12 (2): 268-289.

[11] D. Tan, Y. Tian. Information content of bond liquidity and order flow [J]. China Finance Review International, 2009, 3(1): 1-18. 